\title{
Enzyme/pH-sensitive dendritic polymer-DOX conjugate for cancer treatment
}

\author{
Kai Chen ${ }^{1,2}$, Shuangsi Liao ${ }^{2,3}$, Shiwei Guo ${ }^{1,2}, \mathrm{Hu}$ Zhang $^{4}$, Hao Cai ${ }^{1,2}$, Qiyong Gong ${ }^{2}$, \\ Zhongwei $\mathrm{Gu}^{1,2}$ and Kui Luo ${ }^{1,2^{*}}$
}

\begin{abstract}
It is in a great demand to design a biodegradable, tumor microenvironment-sensitive drug delivery system to achieve safe and highly efficacious treatment of cancer. Herein, a novel pH/enzyme sensitive dendritic pdiHPMADOX conjugate was designed. diHPMA dendritic copolymer with GFLG segments in the branches which are sensitive to the intracellular enzyme of the tumor was prepared through RAFT polymerization. DOX was attached to dendritic diHPMA polymer through a $\mathrm{pH}$-sensitive hydrazone bond. The dendritic pdiHPMA-DOX conjugate self-assembled into nanoparticles with an ideal spherical shape at a mean size of $103 \mathrm{~nm}$. The DOX attached to the polymeric carrier was released in an acidic environment, and the GFLG linker for synthesizing the dendritic vehicle with a high molecular weight $\left(M_{\mathrm{w}}, 220 \mathrm{kDa}\right)$ was cleaved to release low $M_{\mathrm{W}}$ segments $(<40 \mathrm{kDa})$ in the presence of cathepsin $\mathrm{B}$. The dendritic polymeric conjugate was internalized via an endocytic pathway, and then released the anticancer drug, which led to significant cytotoxicity for tumors. The blood circulation time was profoundly prolonged, resulting in high accumulation of DOX into tumors. In vivo anti-tumor experiments with 4T1 tumor bearing mice demonstrated that the conjugate had a better antitumor efficacy in comparison with free DOX. Additionally, body weight measurements and histological examinations indicated that the conjugate showed low toxicities to normal tissues. This dendritic polymeric drug carrier in a response to intracellular enzyme and acidic $\mathrm{pH}$ of tumor tissue or cells holds great promise in tumor-targeted therapy.
\end{abstract}

Keywords: dendritic polymer conjugate, stimuli-responsive, biodegradability, biocompatibility, anti-tumor therapy

\section{INTRODUCTION}

Materials science has developed rapidly in recent years [1-3]. The nanoscale drug delivery system based on organic or inorganic materials has been extensively applied in cancer chemotherapy [4-7]. Although polymeric nanoparticles have many advantages, such as increasing the water solubility of hydrophobic chemotherapeutics, prolonging the blood retention time, improving the safety of chemotherapeutics and increasing accumulation in the tumor tissues through enhanced penetration and retention (EPR) effect [8], there are still some issues to be addressed, such as poor stability during blood circulation, low efficiency in cellular internalization, and toxicity to normal tissues $[9,10]$. To overcome these issues, polymerdrug conjugates based nanoparticles have been developed to improve therapeutic indices and biosafety [11].

In order to design a polymer-doxorubicin (DOX) conjugate with excellent anti-tumor performance, an appropriate polymeric carrier is the cornerstone [12-15]. poly[N-(2-hydroxypropyl) methacrylamide] (polyHPMA) has served as a favorable drug delivery carrier owing to its high solubility in water, biocompatibility, and non-immunogenicity [16-19]. In the early stage in the development of HPMA drug conjugates, HPMA with a high molecular weight (HMW) was directly utilized to conjugate drugs [20]. However, when the $M_{\mathrm{W}}$ of these HPMA polymers is beyond a suitable value $(>40 \mathrm{kDa})$ for prolonging circulation time and enhancing EPR effects [21], the nondegradability of their backbones may cause long-term toxicities. Recently, glycylphenylalanylleucyl-

\footnotetext{
${ }^{1}$ National Engineering Research Center for Biomaterials, Sichuan University, Chengdu 610064, China

${ }^{2}$ Huaxi MR Research Center (HMRRC), Department of Radiology, West China Hospital, Sichuan University, Chengdu 610041, China

${ }^{3}$ College of Life Sciences, Sichuan University, Chengdu 610064, China

${ }^{4}$ School of Chemical Engineering, The University of Adelaide, SA 5005, Australia

*Corresponding author (email: luokui@scu.edu.cn)
} 
glycine tetrapeptide (GFLG) as a biodegradable moiety has been introduced into the HPMA backbone to increase accumulation of the polymer-DOX conjugate in tumors by the EPR effect. After entry into cells, the peptide is degraded and the conjugate becomes low $M_{\mathrm{W}}$ fragments $(<40 \mathrm{kDa})$ for renal clearance [21-23]. In addition, HPMA has only one hydroxyl group, while its similar monomer, $N$-(1,3-dihydroxypropan-2-yl) methacrylamide (diHPMA), has two hydroxyl groups. Therefore, diHPMA polymers may have better water-solubility and can be explored as an efficient drug delivery system.

Compared to linear polymeric carriers for drug delivery, the dendritic configuration with a rigid architecture could achieve much longer blood circulation time and accumulate more in tumors through the EPR effect $[8,24]$. These dendritic polymer-drug conjugates have demonstrated their great potential as efficient anticancer agents [25]. Such conjugates avoid haunting issues associated with free DOX [26]: severe adverse effects for high doses and repeated administrations; cardiac toxicity, liver injury, bone marrow hematopoietic dysfunction after long-term treatment, rapid clearance in kidney and ineffective accumulation in the tumor tissues after intravenous injection [27]. In our previous studies, peptide dendritic polymer-drug conjugates were prepared through organic synthesis or reversible addition-fragmentation chain-transfer (RAFT) polymerization with the aim of eliminating the issues from free DOX [28-30].

In this study, we synthesized a dendritic conjugate (pdiHPMA-DOX) by RAFT polymerization and conjugating chemistry, as shown in Scheme 1. The physiochemical properties of the conjugate were characterized. The ex-vivo drug release and in vitro cytotoxicity of the conjugate were examined. Cellular internalization and intracellular trafficking of this conjugate were observed by a confocal microscope. Meanwhile, apoptosis induced by the conjugate was analyzed by flow cytometry. In addition, the pharmacokinetics of the conjugate was measured in the normal mice. Finally, the antitumor efficacy of the dendritic pdiHPMA-DOX conjugate was assessed in a $4 \mathrm{~T} 1$ xenograft mouse model.

\section{EXPERIMENTAL SECTION}

\section{Materials and instruments}

The VA044, cathepsin B, DOX and trifluoroacetic acid (TFA) were purchased from Sigma-Adrich (USA). Monomers diHPMA, MA-GFLGK-MA, MA-GFLG-CTA and MA-Al-NHNHBoc were prepared according to previous reports [22,29,31]. Fetal bovine serum, penicillin/ streptomycin, and medium RPMI 1640 were obtained from HyClone (USA). Hoechst 33342 was obtained from Beyotime (China). Lyso-Tracker Green DND-26 was purchased from Invitrogen (USA). Annexin V-FITC/ propidium iodide (PI) apoptosis detection kit was obtained from 4A Biotech Co., Ltd. (China). The ex-vivo fluorescent images were obtained using Maestro In-Vivo Imaging System (Cri, USA).

\section{Synthesis of dendritic pdiHPMA-DOX conjugate}

The monomers diHPMA $(2.64 \mathrm{~g}, 16.6 \mathrm{mmol})$, MA-AlNHNHBoc $(285 \mathrm{mg}, \quad 1.05 \mathrm{mmol}), \quad$ MA-GFLGK-MA $(115 \mathrm{mg}, \quad 175 \mu \mathrm{mol})$ and MA-GFLG-CTA $(46.4 \mathrm{mg}$, $61 \mu \mathrm{mol})$ were put in a vial under protection with nitrogen. The solvent of water/methanol $(1: 2,14 \mathrm{~mL})$ with VA044 $(7 \mathrm{mg}, 21.7 \mu \mathrm{mol})$ were added. The mixture was bubbled with nitrogen for $40 \mathrm{~min}$, and the polymerization was mediated at $45^{\circ} \mathrm{C}$ for $14 \mathrm{~h}$. After stirred at $0^{\circ} \mathrm{C}$ in air for $10 \mathrm{~min}$, the solution was dropped into acetone, and the solid was collected. The crude products were purified via size-exclusion chromatography (SEC) on an ÄKTA/ FPLC system (GE Healthcare), where the column was Superose 6 HR10/30 column and mobile phase was sodium acetate buffer/acetonitrile (7:3, pH 6.5). The fractions with polymers were collected, dialyzed against water, freeze dried, resulting in slight pink product (Dendritic pdiHPMA-NHNHBoc copolymer, $1.88 \mathrm{~g}$, $60.5 \%$ yield). The content of amino acids (GFLGK) was tested via the amino acid analysis, and the percent weight of the amino acids Gly, Phe, Leu and Lys were $1.79 \%$, $1.94 \%, 1.52 \%$ and $1.33 \%$, respectively.

The Boc groups in the dendritic copolymer $(1.5 \mathrm{~g})$ was removed in trifluoroacetic acid (TFA, $10 \mathrm{~mL}$ ). After stirred for $4 \mathrm{~h}$, the solvents were removed, and $20 \mathrm{~mL}$ water was added. The solution was then dialyzed against water for $18 \mathrm{~h}$, freeze dried, giving the white powder. This powder and $400 \mathrm{mg} \mathrm{DOX} \cdot \mathrm{HCl}$ was dissolved in $10 \mathrm{~mL}$ $\mathrm{NH}_{4} \mathrm{OAc}$ buffer $\left(0.1 \mathrm{~mol} \mathrm{~L}^{-1}, \mathrm{pH}\right.$ 5.7). The solution was stirred at $28^{\circ} \mathrm{C}$ for $36 \mathrm{~h}$, dialyzed against water for $36 \mathrm{~h}$, freeze dried, giving the red powder (Dendritic pdiHPMADOX conjugate, $1.54 \mathrm{~g}$ ). The drug content was tested by a UV-vis spectrophotometry, resulting in $5.1 \%$ by weight percent. ${ }^{1} \mathrm{H}$ NMR data was measured by a $400 \mathrm{MHz}$ Bruker Advanced Spectrometer. Size exclusion chromatography (SEC) (GE Healthcare) was used to determine the $M_{\mathrm{W}} \mathrm{s}$ and polydispersity (PDI) of the copolymer.

\section{Size, zeta potential and morphology}

The nanoparticle hydrodynamic diameter and zeta potential were measured in double distilled water 


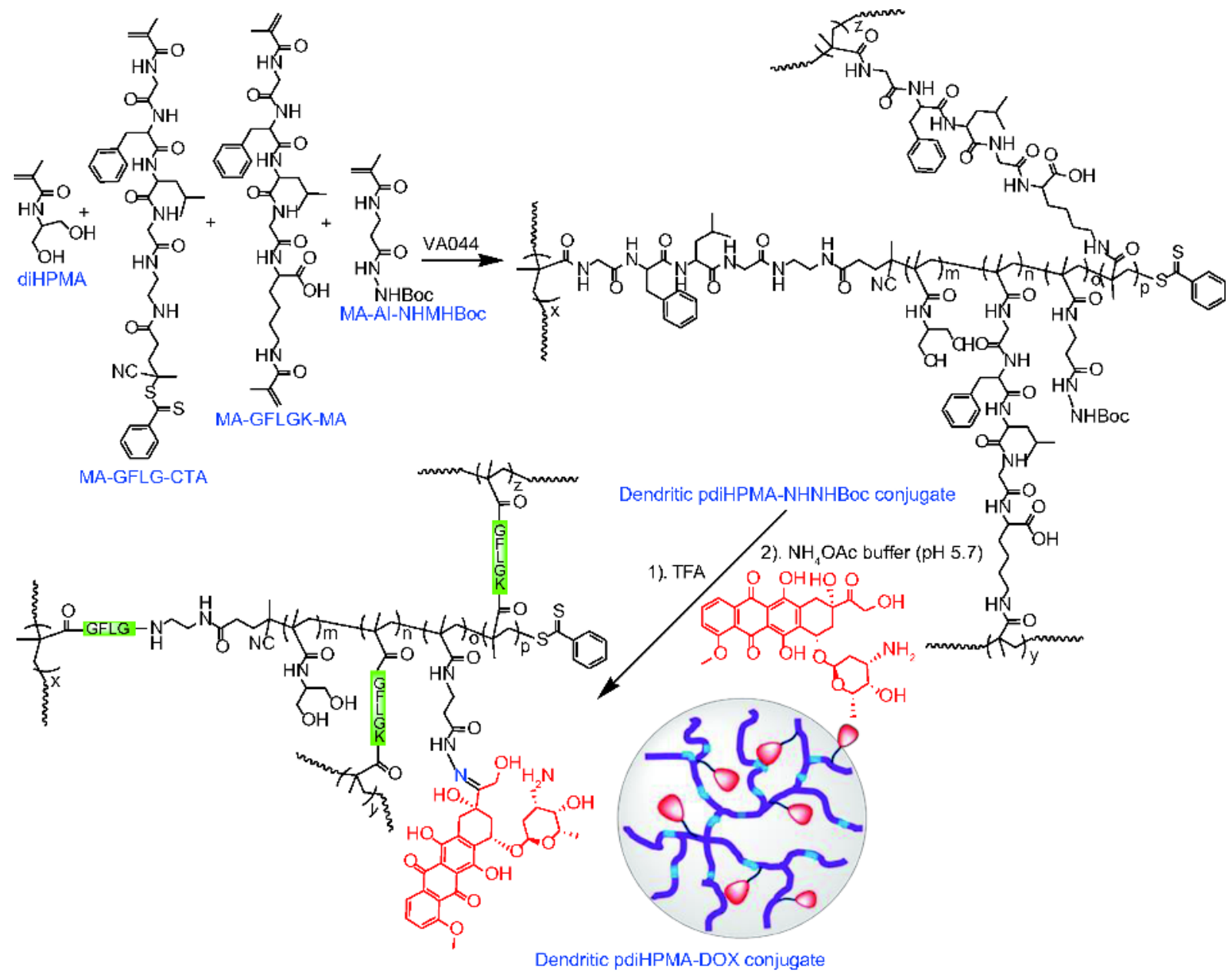

Scheme 1 Preparation of the dendritic pdiHPMA-DOX conjugate.

(2 $\mathrm{mg} \mathrm{mL}^{-1}$ ) by a Zetasizer Nano ZS (Malvern Instruments, Worcestershire, UK). The measurements were repeated three times. The morphology of the nanoparticles was observed under a scanning electron microscope (SEM, S-3400N II electron microscope, Hitachi). The conjugate was dispersed in double distilled water and then $10 \mu \mathrm{L}$ solution was dropped onto a clean silicon slice. After evaporation at room temperature, the samples were examined under the SEM.

\section{In vitro stability evaluation}

Dendritic conjugate $(4 \mathrm{mg})$ was dispersed in $2 \mathrm{~mL}$ PBS containing $50 \% \mathrm{FBS}$ at $37^{\circ} \mathrm{C}$ at a moderate shaking speed of $30 \mathrm{rpm}[32,33]$. At predetermined time points $(0,2,4$, 8,12 and $24 \mathrm{~h}$ ), $200 \mu \mathrm{L}$ of the solution was taken and placed in a 96-well plate. The transmittance at $750 \mathrm{~nm}$ was measured through a microplate reader (Thermo Scientific Varioskan Flash, USA). Zeta potential and particle size were monitored using the Zetasizer Nano ZS.

\section{In vitro biodegradability assay}

The enzymatic degradation of the dendritic pdiHPMADOX conjugate was examined in Mcllvaine's buffer ( $\mathrm{pH}$ 5.0) with $2.8 \mu \mathrm{mol} \mathrm{L}^{-1}$ cathepsin B. The conjugate $(6 \mathrm{mg})$ was dispersed in $1 \mathrm{~mL}$ of the prepared buffer, and the mixture was filtered with a $0.45 \mu \mathrm{m}$ filter membrane and incubated for $0,2,4,8,10 \mathrm{~h}$ at $37^{\circ} \mathrm{C}$. At selected time points, $200 \mu \mathrm{L}$ of the samples were determined by SEC.

\section{In vitro release of DOX from the conjugate}

The dendritic pdiHPMA-DOX conjugate was dispersed in $2 \mathrm{~mL}$ Mcllvaine's buffer with two $\mathrm{pH}$ values of 7.4 and 5.0 in the presence or absence of cathepsin B. The solution was then placed in a bag filter $\left(M_{\mathrm{W}}\right.$ cutoff: $\left.3,500 \mathrm{Da}\right)$. Subsequently, this membrane bag was transferred into a $50 \mathrm{~mL}$ centrifuge tube by adding $30 \mathrm{~mL}$ of McIlvaine's 
buffer with different $\mathrm{pH}$ values. The centrifuge tube was placed horizontally in a shaking bath at $37^{\circ} \mathrm{C}$ at $60 \mathrm{rpm}$. At the selected time point, $2 \mathrm{~mL}$ permeate was collected and replenished with $2 \mathrm{~mL}$ fresh buffer solution so as to keep the sink condition. The permeate was measured by fluorospectrophotometer to analyze the DOX concentration released from the conjugate.

\section{Cells culture and animals}

4T1 cell line was obtained from Chinese Academy of Sciences Cell Bank for Type Culture Collection (Shanghai, China). The $4 \mathrm{~T} 1$ cell was cultured in RPMI 1640 medium (Life Technologies), containing 10\% ( $w / v)$ FBS (Hyclone), $100 \mathrm{U} \mathrm{mL}^{-1}$ of penicillin, and $100 \mathrm{mg} \mathrm{mL}^{-1}$ of streptomycin at $37^{\circ} \mathrm{C}$ with the continuous supply of air containing 5\% $\mathrm{CO}_{2}$. Six- to eight-week-old female $\mathrm{Balb} / \mathrm{c}$ mice with their body weights in the range of 18.0 to $22.0 \mathrm{~g}$ were used for in vivo experiments. The animals were obtained from Chengdu DaShuo Biological Technology Co., Ltd., and they were maintained in a room at a constant temperature of $24^{\circ} \mathrm{C}$ with a cycle of $12 \mathrm{~h}$ light/ darkness. All animal experiments conducted were in compliance with national guidelines. The Animal Care and Use Committee of Sichuan University approved the animal studies.

\section{Cytotoxicity assays}

Briefly, 4T1 cells were seeded in a 96 -well plate $(5,000$ cells per well) and cultured for $24 \mathrm{~h}$. After full attachment, 4T1 cells were exposed to fresh medium containing the dendritic pdiHPMA-DOX conjugate or free DOX (0-90 $\mu \mathrm{g} \mathrm{mL}^{-1}$ equivalents) for $48 \mathrm{~h}$. Subsequently, the cell survival rates were measured by the standard CCK8 kit assay. The absorbance of each well was measured by a microplate reader. Cell survival rates of free DOX and dendritic pdiHPMA-DOX conjugate groups were normalized to that of control cells with no treatment. The drug concentration with $50 \%$ inhibition $\left(\mathrm{IC}_{50}\right)$ was determined by GraphPad Prism software (Version 6.0, GraphPad Software, USA). The cytotoxicity of the drugfree conjugate on $4 \mathrm{~T} 1$ cells was evaluated in a similar approach as above.

\section{Cellular uptake studies}

For cell imaging study, $5 \times 10^{5} 4 \mathrm{~T} 1$ cells were cultured on $35 \mathrm{~mm}$ glass microwell dishes. After $36 \mathrm{~h}$ incubation in 1640 medium at $37^{\circ} \mathrm{C}$, the culture medium was discarded. Cells were treated with free DOX and dendritic pdiHPMA-DOX conjugate at an equivalent DOX concentration of $5 \mu \mathrm{g} \mathrm{mL} L^{-1}$, respectively, and further incubated for 0.5 ,
2, $4 \mathrm{~h}$. Afterwards, the cells were rinsed with PBS, fixed with $4 \%$ paraformaldehyde solution, and stained with Hoechst $33342\left(10 \mu \mathrm{g} \mathrm{mL}^{-1}\right)$. Cell images were observed under a confocal laser scanning microscopy (CLSM, Leica TCS SP2, Germany).

\section{Subcellular localization of dendritic pdiHPMA-DOX conjugate}

The $4 \mathrm{~T} 1$ cells were planted on a glass bottom dish at a density of $10^{5}$ cells/dish and then exposed to the dendritic pdiHPMA-DOX conjugate at a DOX concentration of $5 \mu \mathrm{g} \mathrm{mL}^{-1}$ for $4 \mathrm{~h}$. Lyso-Tracker Green $\left(250 \mathrm{nmol} \mathrm{L}^{-1}\right)$ was used to stain lysosomes of $4 \mathrm{~T} 1$ cells for $1.5 \mathrm{~h}$. Subsequently the nuclei were counterstained with Hoechst $33342\left(10 \mu \mathrm{g} \mathrm{mL}^{-1}\right)$ for $15 \mathrm{~min}$. After the cells were rinsed three times with PBS, a CLSM was used to record fluorescence images.

\section{Apoptosis assay}

Apoptosis of the $4 \mathrm{~T} 1$ cells induced by dendritic conjugate was analyzed by flow cytometry. 4T1 cells were cultured in a 6-well plate at a density of $10^{5}$ cells/well and incubated for $24 \mathrm{~h}$. Thereafter, the cells were treated with free DOX or the dendritic pdiHPMA-DOX conjugate at an equivalent DOX concentration of $0.5 \mu \mathrm{g} \mathrm{mL} \mathrm{L}^{-1}$, respectively. After the cells were incubated for additional $48 \mathrm{~h}$, propidium iodide (PI)/Annexin V-FITC Kit (4A Biotech Co., Beijing, China) was utilized to detect apoptotic cells by a flow cytometer. Briefly, cells were washed with cold PBS and detached through trypsinization. The cells were collected by centrifugation and rinsed twice with ice-cold PBS. Subsequently, $200 \mu \mathrm{L}$ of binding buffer was used to suspend the cells at a density of $1 \times 10^{6}$ cells per mL. $5 \mu \mathrm{L}$ FITC-Annexin V and $5 \mu \mathrm{L}$ PI were added to $200 \mu \mathrm{L}$ of the cell suspension. After gently mixing the solution and $10 \mathrm{~min}$ incubation under room temperature in darkness, the apoptosis rate was analyzed by a flow cytometer (FACS Calibur, BD, USA).

\section{In vivo pharmacokinetics}

To measure blood circulation time of free DOX and the dendritic pdiHPMA-DOX conjugate, $200 \mu \mathrm{L}$ solution at a dose of $5 \mathrm{mg}$ DOX/kg was injected in tumor-free female $\mathrm{Balb} / \mathrm{c}$ mice via the tail vein. At $5 \mathrm{~min}, 15 \mathrm{~min}, 30 \mathrm{~min}$, $1 \mathrm{~h}, 2 \mathrm{~h}, 4 \mathrm{~h}, 8 \mathrm{~h}$ and $12 \mathrm{~h}$ post administration, $20 \mu \mathrm{L}$ blood samples were harvested from the retro-orbital plexus of the eye, and transferred into $1.5 \mathrm{~mL}$ EP tube with $80 \mu \mathrm{L}$ deionized water. The blood samples were then dispersed with $100 \mu \mathrm{L}$ acetonitrile followed by $5 \mathrm{~min}$ sonication to extract DOX. Afterwards, all samples were 
stored at $4^{\circ} \mathrm{C}$ overnight. Thereafter, the sample mixtures were centrifuged to precipitate insoluble constituents, and $100 \mu \mathrm{L}$ of the supernatant was collected and placed onto a 96-well plate (per well). Fluorescence of DOX at selected time points was detected on a microplate reader at an excitation wavelength of $485 \mathrm{~nm}$ and an emission wavelength of $555 \mathrm{~nm}$. A linear standard curve of DOX was established to quantify the concentration of DOX in samples. Pharmacokinetic parameters were assayed by fitting the DOX concentrations in blood to a non-compartment model with PK Solver software as previous report [34].

\section{Therapeutic evaluation of dendritic pdiHPMA-DOX conjugate}

Tumor bearing mice were established by implanting $5 \times 10^{6} 4 \mathrm{~T} 1$ cells at the right flank in Female Balb/c mice. After the tumor volume reached around $50 \mathrm{~mm}^{3}$, mice were randomly assigned into three groups $(n=7)$. Mice were then intravenously injected with $200 \mu \mathrm{L}$ of the dendritic pdiHPMA-DOX conjugate or free DOX via the tail vein at a DOX dose of $5 \mathrm{mg} \mathrm{kg}^{-1}$ on $1^{\text {st }}, 5^{\text {th }}, 9^{\text {th }}, 13^{\text {th }}$, $17^{\text {th }}$ and $21^{\text {st }}$ days. The tumor volume was estimated from the formula: $V=\left(L \times W^{2}\right) / 2$, and the relative tumor volume was calculated as $V / V_{0}$, where $L$ and $W$ referred to the length and width of the tumor, respectively and $V_{0}$ was the tumor volume at the first administration. Body weight and tumor volume were monitored every two days. After 27 days of treatment, mice were sacrificed, and the tumors were collected and weighed to evaluate the tumor growth inhibition (TGI). TGI was defined as: TGI $=(1$ -(mean tumor weight of treatment group)/(mean tumor weight of control group) $) \times 100 \%$ [14]. Major organs including kidney, heart, spleen, lung and liver were harvested and fixed with 10\% formaldehyde in PBS solution for histological analysis.

\section{Statistical analysis}

Data were presented as mean \pm standard deviation (SD). Statistical significance was calculated by analysis of variance and paired two-tailed Student's $t$-test. A $p$-value less than 0.05 was considered as statistically significant.

\section{RESULTS AND DISCUSSION}

\section{Preparation and characterization of dendritic conjugate}

To prepare biodegradable dendritic polymer, the methacrylate and peptide GFLG-functionalized chain transfer agent (MA-GFLG-CTA) were employed to mediate the RAFT polymerization, while the di-methacrylate GFLGK

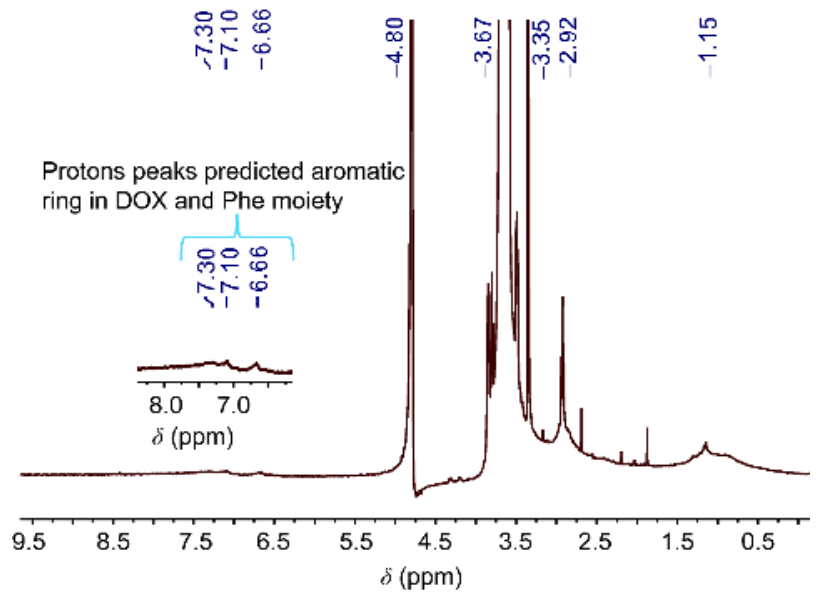

Figure 1 The ${ }^{1} \mathrm{H}$ NMR spectra of the dendritic pdiHPMA-DOX conjugate recorded in $\mathrm{D}_{2} \mathrm{O}$.

linker (MA-GFLGK-MA) was added to increase the linking of linear polymeric chains into dendritic structures. In the ${ }^{1} \mathrm{H}$ NMR spectra of dendritic pdiHPMADOX in Fig. 1, the obvious peaks at $6.66-7.30 \mathrm{ppm}$ are assigned to the aromatic ring protons from the DOX and Phe moiety. The color of the solution of the dendritic pdiHPMA-DOX is red, indicating the DOX has been successfully attached to the polymeric carrier.

The as-prepared dendritic pdiHPMA-DOX conjugate self-assembled into nanoparticles in aqueous solution owing to its hydrophilic chain (pdiHPMA) and hydrophobic fragments (DOX and GFLG) at room temperature. The morphology of dendritic conjugate was spherical with a diameter of roughly $95 \mathrm{~nm}$ determined by SEM (Fig. 2a). The hydrodynamic diameter of dendritic conjugate was $103 \mathrm{~nm}$ measured by DLS (Fig. 2b). The overall zeta potential of dendritic conjugate was found to be slightly negatively charged $(-4.52 \mathrm{mV}$ ) (Fig. S1). Nanoparticles in this size range and with a negative zeta potential may have longer blood circulation time and accumulate more in the tumor sites through the EPR effect $[35,36]$.

\section{Stability of the pH-sensitive dendritic conjugate}

The stability of nanoparticles during blood circulation is essential for passive accumulation in tumors [37]. PBS with 50\% FBS was used to mimic the biological fluids, and it was used for evaluate the stability of dendritic conjugate. The transmittance of the mixture remained nearly unchanged at selected time points. In addition, no obvious changes in the particle diameter and zeta potential of dendritic conjugate were observed within $24 \mathrm{~h}$ incubation (Fig. S2). All these results suggested that there 

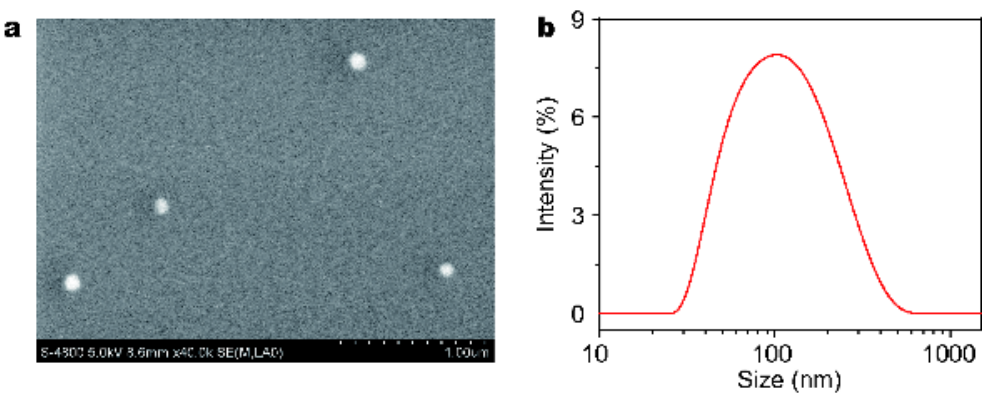

Figure 2 Particle size of dendritic conjugate. (a) SEM images. (b) Size distribution by dynamic light scattering (DLS).
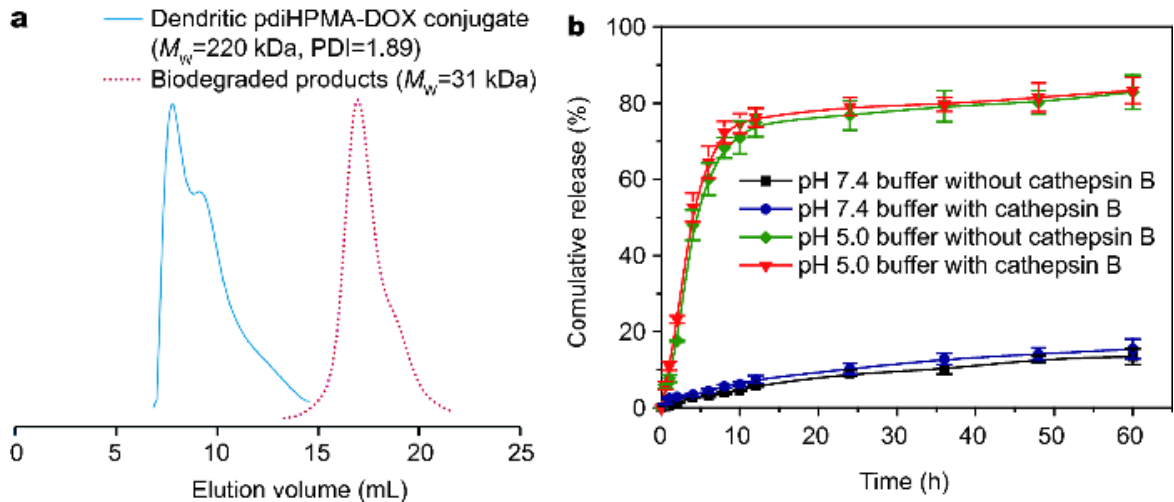

Figure 3 (a) SEC profiles of dendritic conjugate and degraded product. (b) Cumulative DOX release profile from the dendritic conjugate at $\mathrm{pH} 5.0$ and $\mathrm{pH} 7.4$ at $37^{\circ} \mathrm{C}$. The buffer was mixed with or without cathepsin B. The data shown are mean \pm SD $(n=3)$.

was no profound aggregation of dendritic conjugate in PBS with 50\% FBS and dendritic conjugate exhibited much favorable serum stability for $24 \mathrm{~h}$. The excellent stability of dendritic conjugate might be ascribed to the overall negative surface charge of dendritic conjugate that could minimize the interaction between dendritic conjugate and plasma proteins and prevent drug leakage during blood circulation. Moreover, the stability may prolong the blood circulation half-life and improve the efficiency in drug delivery into tumor tissues in vivo [3739].

\section{In vitro degradation of the dendritic conjugate}

The biodegradable diblock copolymer with a $M_{\mathrm{W}}$ $(220 \mathrm{kDa})$ above the renal threshold $(40 \mathrm{kDa})$ was linked by the GFLG peptides. After $10 \mathrm{~h}$ incubation with cathepsin $\mathrm{B}$, this copolymer was degraded into the products with a low $M_{\mathrm{W}}$ of $31 \mathrm{kDa}$ (under the renal threshold) (Fig. $3 \mathrm{a})$, and the $M_{\mathrm{W}}$ of degraded fragments at predetermined time points were presented in Table S1. Rapid degradation of the copolymer was due to enzymatic attack to the oligopeptide sequence GFLG in the branched chain. In contrast, the $M_{\mathrm{W}}$ remained nearly identical when the copolymers were incubated in PBS ( $\mathrm{pH}$ 7.4) without cathepsin B. It was reported that the cathepsin B was overexpressed in cancer cells but maintained at a very low level in normal tissues and blood [40]. Thus the copolymers with a high $M_{\mathrm{W}}$ were not degraded during blood circulation, whereas they may be decomposed in the tumor after they passively accumulate in the tumor tissue/ cells.

\section{Drug release from the dendritic conjugate}

The drug release profile of dendritic conjugate was examined using a dialysis at $\mathrm{pH} 7.4$ and 5.0 with or without cathepsin B. As shown in Fig. 3b, DOX release from the pdiHPMA-DOX conjugate based nanoparticles with or without cathepsin B at pH 7.4 was far slower than that at $\mathrm{pH}$ 5.0. At the same $\mathrm{pH}$ condition, no significant difference in DOX release curves was observed between the buffer with and without cathepsin B. This result suggested that enzyme had no effect on drug release. After $10 \mathrm{~h}$ incubation, $74.7 \%$ of DOX was released at $\mathrm{pH} 5.0$ with cathepsin B, while only $6.2 \%$ at $\mathrm{pH}$ 7.4. As the incubation time was extended to $60 \mathrm{~h}, 15.5 \%$ of DOX was released from nanoparticles at $\mathrm{pH} 7.4$ with cathepsin $\mathrm{B}$. The rapid 

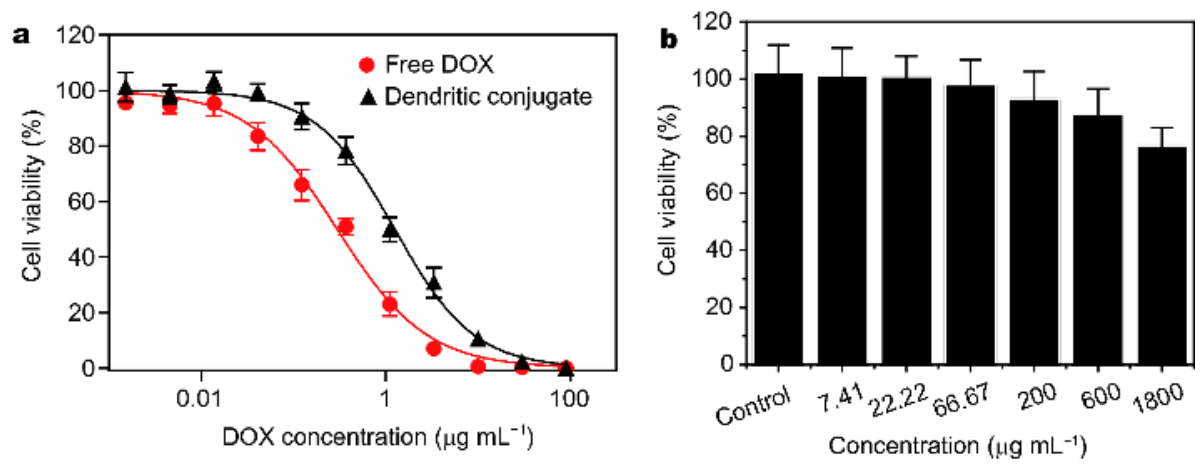

Figure 4 Cytotoxicity of the dendritic conjugate (a) and the drug-free dendritic conjugate against $4 \mathrm{~T} 1 \mathrm{cells}$ (b) incubation for $48 \mathrm{~h}$ at different concentrations. The data shown are mean $\pm \mathrm{SD}(n=5)$.

drug release at $\mathrm{pH} 5.0$ was due to cleavage of the hydrazone linkage in an acidic environment. Additionally, the considerably slow drug release implied that the hydrazone bond in the dendritic pdiHPMA-DOX conjugate was not susceptible to cleavage at $\mathrm{pH}$ 7.4. Therefore, the conjugate remained stable in normal tissues and during blood circulation.

\section{In vitro cytotoxicity of the $\mathrm{pH}$-sensitive dendritic conjugate}

The cell viability by the CCK-8 assay was shown in Fig. 4 . The pdiHPMA-DOX conjugate exhibited weaker inhibition of $4 \mathrm{~T} 1$ cell growth than free DOX (Fig. 4a). The $\mathrm{IC}_{50}$ of dendritic conjugate $\left(2.155 \mu \mathrm{mol} \mathrm{L} \mathrm{L}^{-1}\right)$ was higher than that of free DOX $\left(0.52 \mu \mathrm{mol} \mathrm{L}{ }^{-1}\right)$. The lower $\mathrm{IC}_{50}$ of free DOX could be due to its rapid diffusion into cells. However, the endocytosis pathway was adopted to uptake dendritic conjugate with a high $M_{\mathrm{w}}$. It has been reported that the internalization speed for the endocytosis pathway was remarkably slower than free diffusion [41]. For this reason, free DOX showed higher cytotoxicity to $4 \mathrm{~T} 1$ cells than dendritic conjugate.

To exclude the contribution of the cytotoxicity from the polymer alone, 4T1 cells were exposed to drug-free

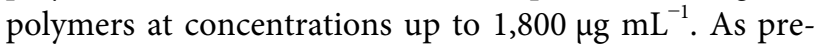
sented in Fig. 4b, the cell survival rate was subtly reduced with an increase of the drug-free conjugate concentration after $48 \mathrm{~h}$ treatment. At a concentration up to $1,800 \mu \mathrm{g} \mathrm{mL} \mathrm{L}^{-1}$, the cell survival rate was still above $76 \%$. These results demonstrated that the drug-free dendritic pdiHPMA and its degraded components had a low cytotoxicity to $4 \mathrm{~T} 1$ cells and could be used as biocompatible drug carriers.

\section{Cellular uptake}

The cellular uptake of free DOX (Fig. 5a) and dendritic conjugate (Fig. 5b) were investigated with the $4 \mathrm{~T} 1$ cells under a CLSM. The red fluorescence of DOX was profoundly enhanced with extension of the incubation time to $4 \mathrm{~h}$ for both free DOX and dendritic conjugate. Red fluorescence was found to be significantly weak inside the nuclei of $4 \mathrm{~T} 1$ cells for dendritic conjugate at $0.5 \mathrm{~h}$, and it was mainly distributed in the cytoplasm. After incubation for $4 \mathrm{~h}$, red fluorescence was found inside the nuclei in the dendritic conjugate group. On the contrary, very strong red fluorescence was found in the nuclei in the free DOX group at $0.5 \mathrm{~h}$, indicating rapid cellular uptake of free DOX occurred, which was consistent with the cytotoxicity results. The higher level of internalization of free DOX than dendritic conjugate might be attributed to diffusion due to concentration gradients [30]. While multiple endocytosis ways were involved with cellular uptake of dendritic conjugate by $4 \mathrm{~T} 1$ cells, and the uptake rate was much slower than free diffusion $[42,43]$.

\section{Intracellular trafficking of the dendritic conjugate}

Intracellular trafficking of dendritic conjugate was also elucidated under the CLSM. Lysosomes of 4T1 cells were stained with Lysotracker Green, while the cell nuclei with Hoechst 33342. DOX emitted red fluorescence. The individual fluorescence and merged one were shown in Fig. 6a. Yellow fluorescence was noticed in the merged image post $4 \mathrm{~h}$ incubation and it appeared as a result of overlapping red and green fluorescence, which revealed dendritic conjugate were mainly located in endosomes/ lysosomes. Red fluorescence alone was found in some nuclei, which suggested that DOX had successfully escaped from the lysosomes due to cleavage of the hydrazone bond between DOX and the polymer in the acidic environment (Fig. 3b). However, for free DOX, very strong red fluorescence was observed only in the nuclei, not the acidic organelles after $4 \mathrm{~h}$ treatment. These 

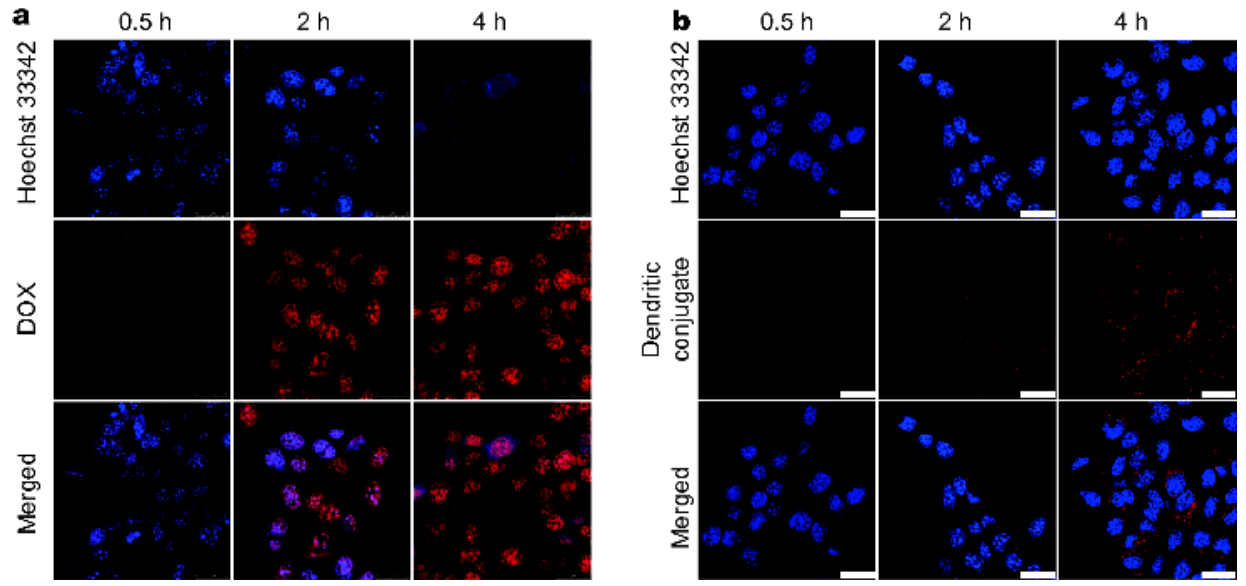

Figure 5 In vitro cellular uptake of free DOX (a) and the dendritic conjugate (b) in $4 \mathrm{~T} 1$ cells after incubation for 0.5, 2, and $4 \mathrm{~h}$ under a CLSM. Cell nuclei were stained with Hoechst 33342. Bar $=25 \mu \mathrm{m}$.

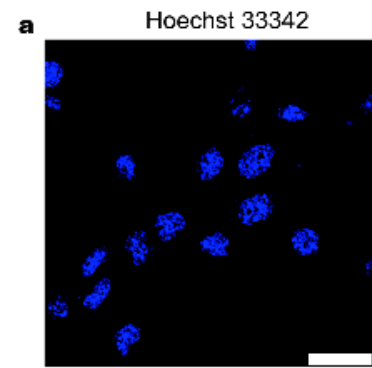

b

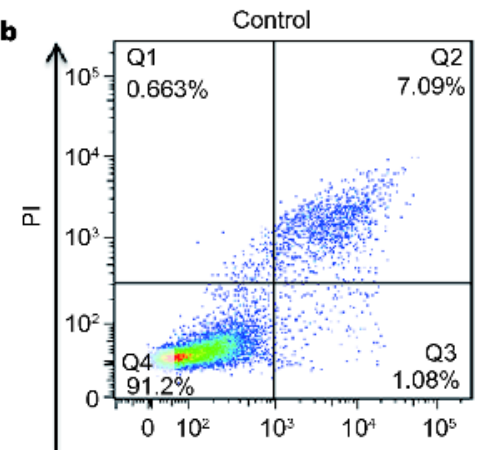

Lyso-tracker

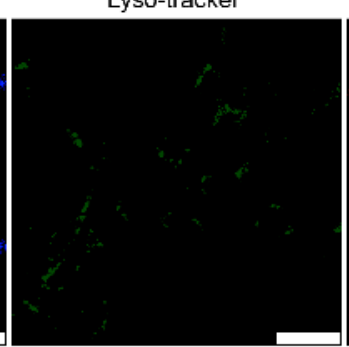

Dendritic conjugate

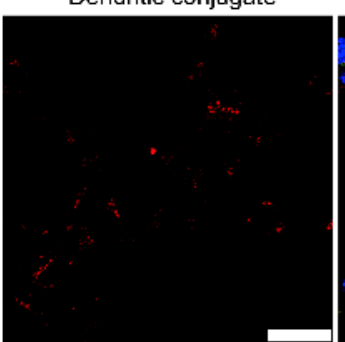

Merged

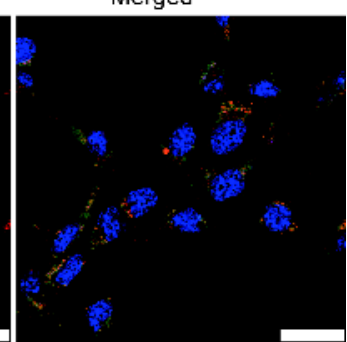

Dendritic conjugate
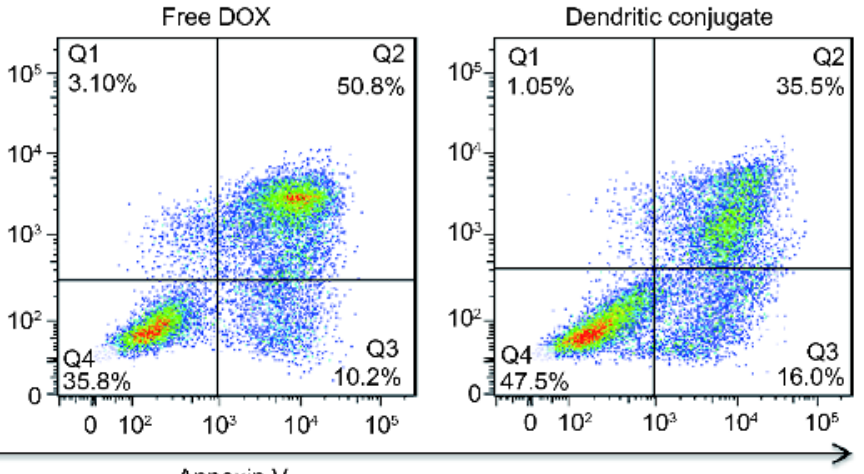

Figure 6 (a) Confocal images of cellular uptake of the dendritic conjugate by $4 \mathrm{~T} 1$ cells after $4 \mathrm{~h}$ of incubation with the conjugate at $37^{\circ} \mathrm{C}$. The acidic organelles were stained with Lysotracker Green, and cell nuclei with Hoechst 33342. Scale bars: $25 \mu \mathrm{m}$. (b) Analysis of $4 \mathrm{~T} 1$ cell apoptosis induced by free DOX and the dendritic conjugate after $48 \mathrm{~h}$ incubation by flow cytometry.

results confirmed that the dendritic conjugate carried the drugs into cancer cells through endocytosis, was trafficked through the endolysosomal pathways [44], and finally released the drug in the acidic organelles for its therapeutic function.

\section{Cellular apoptosis induced by dendritic conjugate}

To further elucidate the anticancer effect of free DOX and dendritic conjugate, the apoptosis rate of $4 \mathrm{~T} 1$ cells induced by two drug formulations was quantified. The cells were exposed to free DOX and dendritic conjugate at an equivalent DOX concentration of $0.5 \mu \mathrm{g} \mathrm{mL} \mathrm{L}^{-1}$ for $48 \mathrm{~h}$ and they were treated using the AnnexinV/PI kit by flow cytometry [45]. As shown from the dot plots in Fig. 6b, the population percentage of late apoptotic $4 \mathrm{~T} 1$ cells with Annexin V+/PI+ was $51 \%$ after cells were treated with 
free DOX, while $7.1 \%$ for the control, and $35.2 \%$ for the dendritic conjugate groups. About $11.2 \%$ and $16.1 \%$ of $4 \mathrm{~T} 1$ cells were in the early apoptosis with Annexin V+ /PI- after exposed to free DOX and dendritic conjugate, respectively, both higher than the control group (1.1\%). In addition, the data of three parallel experiments on apoptosis was summarized in a column diagram (Fig. S3). Significantly increased apoptosis rate was observed in dendritic conjugate treated cells. Therefore, dendritic conjugate induced early and late apoptosis for 4T1 cells, accounting for half population of the treated cells, while free DOX was the most potent in induction of late apoptosis.

\section{Blood circulation}

Prolonged retention of dendritic conjugate in the blood circulation system without clearance from the body is essential for efficient targeted delivery and favorable therapeutic effect [46]. The pharmacokinetics of free DOX and dendritic conjugate were investigated in tumorfree Balb/c mice following bolus intravenous injection of both drug formulations. The time-dependent DOX concentration in the blood was presented in Fig. 7. It was clearly seen that dendritic conjugate had a longer retention time during blood circulation than free DOX. Moreover, the pharmacokinetic parameters were calculated through a non-compartment model (Table S2). Peak concentration $\left(C_{\max }\right)$, half-time $\left(t_{1 / 2}\right)$ and area under the curve (AUC) of dendritic conjugate were 3.56, 8.53, and 22.35-fold higher, respectively, than those of free DOX. It was demonstrated that after DOX was conjugated to the dendritic pdiHPMA, the self-assembled nanoparticles exhibited a profoundly longer retention time in the blood

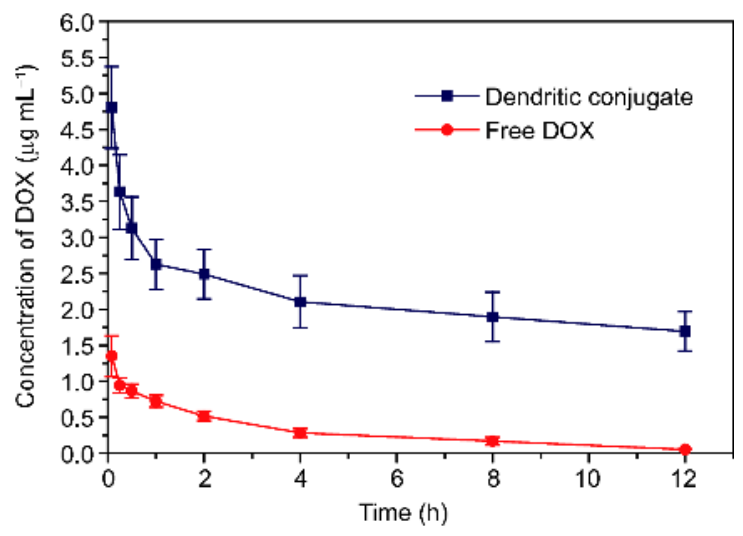

Figure 7 Pharmacokinetic profiles of free DOX and the dendritic conjugate after injection in healthy mice at a DOX dose of $5 \mathrm{mg} \mathrm{kg}^{-1}$ body weight. The data represent the mean $\pm \mathrm{SD}(n=5)$. circulation system. The hydrophilic pdiHPMA on the nanoparticle surface may reduce opsonization in blood and cellular uptake by the reticuloendothelial system. Other pharmacokinetic data of the pdiHPMA-DOX conjugate also outperformed those of free DOX. Compared to linear $[13,34]$ or cross-linked HPMA-DOX conjugate [35], this dendritic conjugate showed longer $t_{1 / 2}$. The results indicate that dendritic structure and higher molecular weight could increase the blood circulation time of polymer drug conjugate.

\section{In vivo antitumor activities of dendritic conjugate}

In vivo therapeutic efficacy of free DOX and dendritic conjugate was examined in a $4 \mathrm{~T} 1$ cancer model. The results in Fig. 8a showed that, on the $27^{\text {th }}$ day, the tumor volume in the mice injected with free DOX at $5 \mathrm{mg}$ DOX per $\mathrm{kg}$ body weight was slightly reduced, while around $79 \%$ of the tumor volume relative to the saline group was still inside the mice after the treatment. However, a profound reduction in the tumor volume relative to the control group, up to $20 \%$, was found for the dendritic conjugate groups at the same dose of DOX. After treatment, all the mice were sacrificed and tumor tissues were collected and weighed (Fig. 8b). The tumor weight was in correspondence with the tumor volume for three groups: smaller tumor volume, lighter tumor weight. As presented in Fig. 8c, dendritic conjugate exhibited up to $63 \%$ of TGI in comparison to the saline administration. However, the TGI of free DOX treatment was around $23 \%$, representing a moderate level of suppression of tumor growth. The significant suppression of tumor growth by dendritic conjugate might be ascribed to increased accumulation of DOX-containing dendritic conjugate inside the tumor cells though EPR effect and rapid release of DOX in an acidic environment in the endosomes/lysosomes (Fig. 3b) [47]. It is noted that the in vivo antitumor activities of the dendritic conjugate is better than linear $[13,34]$ or cross-linked HPMA-DOX counterparts [34], which may be further improved by optimization of the architecture and increasing the molecular weight of the conjugates [48-50].

Body weights of mice after administration with the dendritic conjugate, free DOX, and saline were monitored during the course of the experiment (Fig. 8d) until day 27. The dendritic conjugate and the control group were seen with a slight increase in the body weights, while significant loss in the body weight was found in the free DOX group. These results indicated that dendritic conjugate had better biocompatibility and lower systematic toxicity compared to free DOX. 

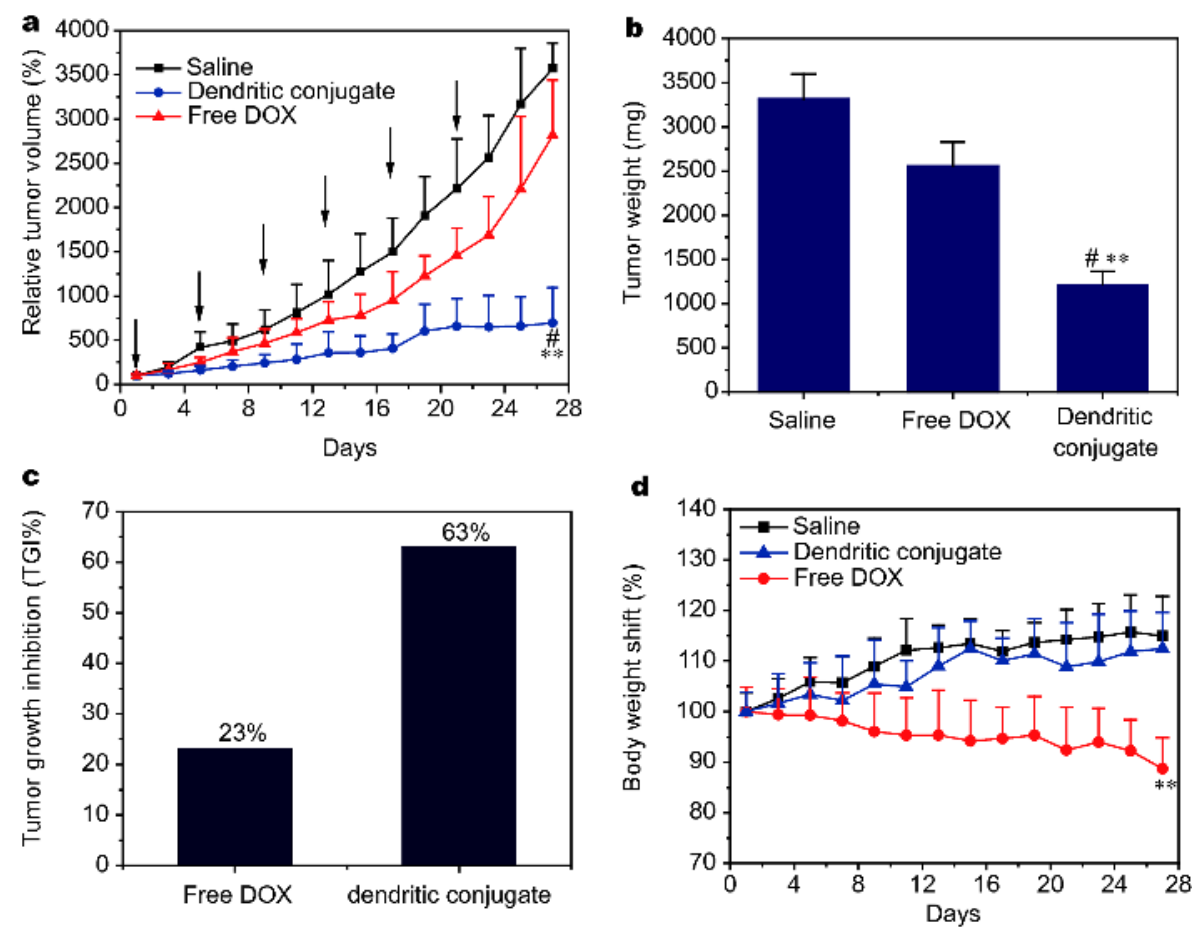

Figure 8 Anti-tumor study in the $4 \mathrm{~T} 1$ breast tumor model $(n=7)$. (a) The dendritic conjugate presented significant tumor suppression $\left({ }^{* *} p<0.01\right.$, compared to saline; ${ }^{p} p<0.05$, compared to free DOX). The black arrows indicate the date of administration via tail vein. (b) On day 27 , weights of tumor tissues. ( $p<0.01$, compared to saline; ${ }^{*} p<0.05$, compared to free DOX). (c) Tumor growth inhibition on the basis of the tumor weight. (d) Monitoring of body weight of the mice administrated with the dendritic conjugate, free DOX, and saline. ( $p<0.01$, free DOX in comparison with saline).

\section{Histopathological analyses}

Long-term toxicity hinders wide application of chemotherapeutic drugs in treating cancer. To further exploit the toxicity and anti-tumor efficacy of dendritic conjugate, the solid organs (kidneys, lung, spleen, liver, and heart) and tumor tissues were collected and prepared for pathological examination. Representative histomorphology images of major organs stained by H\&E were shown in Fig. 9. Histological analysis showed that the free DOXtreated groups exhibited noticeable cardiac toxicity evidenced by blurred heart cell boundaries, disordered cellular arrangements and altered myocardial tissue architecture. However, the heart morphology in the dendritic conjugate treated group was similar to that in the saline-treated mice. Thus, DOX-containing dendritic conjugate were in favor of treating cancer cells with no damage to hearts. It is well known that $4 \mathrm{~T} 1$ cells easily metastasize to lung and liver [51]. As confirmed by H\&E staining, the metastatic foci were clearly seen in lung and liver in both saline and free DOX treated groups (Fig. 9), and these foci were identified by a red dashed line in the H\&E images. In contrast, there was no metastasis in lung and liver of the dendritic conjugate treated mice. H\&E staining was also utilized to examine the morphological changes of tumor tissues. As presented in Fig. S4, the extent of necrosis and apoptosis was in line with that of TGI (Fig. 8c). The tumor tissues in the saline groups exhibited a low level of necrosis and apoptosis with large intact nuclei. Massive chromatins and binucleolates were seen in the tumor tissues, suggesting vigorous cell growth. It was remarkable that tumors treated with dendritic conjugate or free DOX presented a much high level of necrosis, resulting in significant reduction on both cell number and nucleus. The tumor cell nuclei size reduction was found to be associated with shrinkage and fragmentation of cellular nuclei. It was noticed that the necrotic and apoptotic level in the dendritic conjugatetreated group was much higher than that in the free DOX-treated group.

All evidences suggested that DOX-containing dendritic conjugate decreased the cardiotoxicity of free DOX, improved the anti-metastasis efficacy, increased necrosis and apoptosis, and induced effective inhibition of tumor growth in vivo. The favorable safety and effective antitumor therapy of dendritic conjugate may be ascribed to the enhanced DOX accumulation in the tumor site, en- 


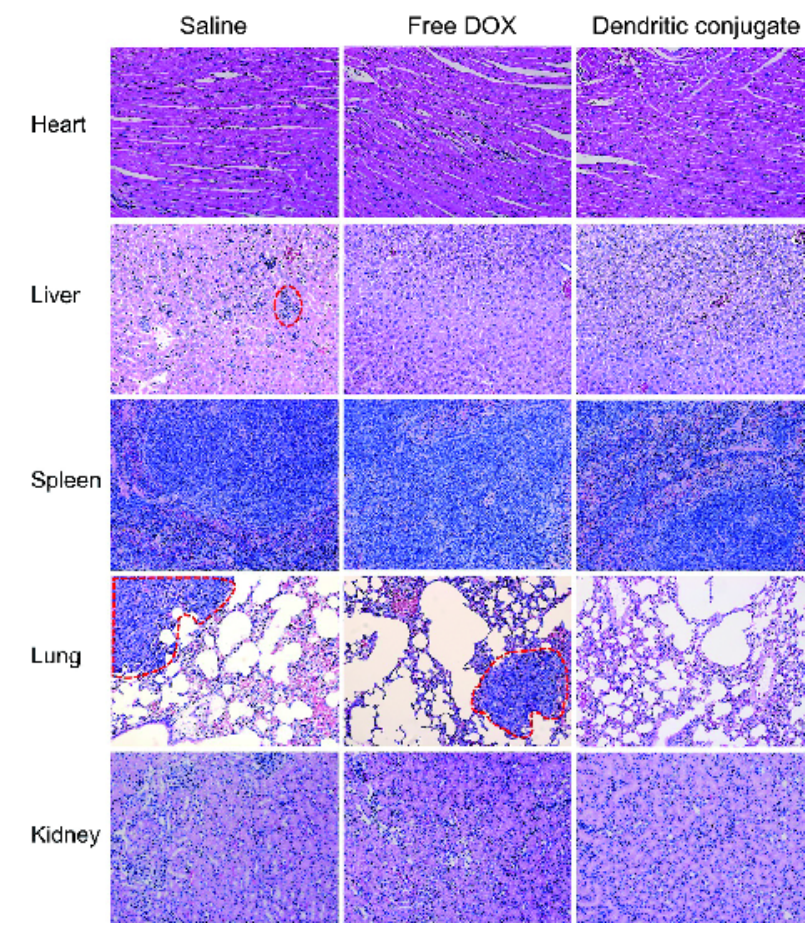

Figure $9 \mathrm{H} \& \mathrm{E}$ staining of major organs harvested from tumor-bearing mice administrated with saline, free DOX and the conjugate $(\times 200)$.

zyme degradation into low $M_{\mathrm{W}}$ segments for renal clearance and $\mathrm{pH}$-triggered release of DOX inside the tumor cells.

\section{CONCLUSIONS}

A novel $\mathrm{pH} /$ enzyme sensitive dendritic pdiHPMA-DOX conjugate was designed and successfully synthetized. This polymeric dendritic conjugate possessed colloidal stability, favorable biocompatibility and responses to acidic $\mathrm{pH}$ for drug release. We have confirmed that the nanoparticles efficiently transported DOX into $4 \mathrm{~T} 1$ cells by the lysosome pathway and effectively inhibited cell proliferation in vitro. Moreover, the cellular apoptosis was induced by dendritic conjugate. A long blood circulation time of dendritic conjugate was found in pharmacokinetics experiments that may increase drug accumulation in tumors through the EPR effect. Furthermore, the dendritic conjugate effectively suppressed $4 \mathrm{~T} 1$ xenograft tumor growth in vivo without DOX-induced systemic toxicity as compared to free DOX. This study indicates that the enzyme/pH responsive dendritic pdiHPMADOX conjugate based nanoparticles are a promising candidate for metastatic cancer treatment.

Received 20 February 2018; accepted 10 April 2018; published online 22 May 2018
1 Li H, Ding Y, Ha H, et al. An all-stretchable-component sodiumion full battery. Adv Mater, 2017, 29: 1700898

2 Treml BE, McKenzie RN, Buskohl P, et al. Soft robotics: autonomous motility of polymer films. Adv Mater, 2018, 30: 1870046

3 Wang F, Xiao J, Chen S, et al. Polymer vesicles: modular platforms for cancer theranostics. Adv Mater, 2018, 28: 1705674

4 Liu Y, Li M, Yang F, et al. Magnetic drug delivery systems. Sci China Mater, 2017, 60: 471-486

5 Jia Q, Chen M, Liu Q, et al. Ethylene glycol-mediated synthetic route for production of luminescent silicon nanorod as photodynamic therapy agent. Sci China Mater, 2017, 60: 881-891

6 Webber MJ, Langer R. Drug delivery by supramolecular design. Chem Soc Rev, 2017, 46: 6600-6620

7 Cai $\mathrm{H}$, Wang $\mathrm{X}$, Zhang $\mathrm{H}$, et al. Enzyme-sensitive biodegradable and multifunctional polymeric conjugate as theranostic nanomedicine. Appl Mater Today, 2018, 11: 207-218

8 Li Y. Realize molecular surgical knife in tumor therapy by nanotechnology. Sci China Mater, 2015, 58: 851-851

9 Blanco E, Shen H, Ferrari M. Principles of nanoparticle design for overcoming biological barriers to drug delivery. Nat Biotechnol, 2015, 33: 941-951

10 Torchilin VP. Multifunctional, stimuli-sensitive nanoparticulate systems for drug delivery. Nat Rev Drug Discov, 2014, 13: 813-827

11 Zhang X, Xia LY, Chen X, et al. Hydrogel-based phototherapy for fighting cancer and bacterial infection. Sci China Mater, 2017, 60: 487-503

12 Anselmo AC, Mitragotri S. An overview of clinical and commercial impact of drug delivery systems. J Control Release, 2014, 190: 1528

13 Dai Y, Cai H, Duan Z, et al. Effect of polymer side chains on drug delivery properties for cancer therapy. J Biomed Nanotechnol, 2017, 13: 1369-1385

14 Pan D, She W, Guo C, et al. PEGylated dendritic diaminocyclohexyl-platinum (II) conjugates as $\mathrm{pH}$-responsive drug delivery vehicles with enhanced tumor accumulation and antitumor efficacy. Biomaterials, 2014, 35: 10080-10092

15 She $\mathrm{W}$, Luo $\mathrm{K}$, Zhang C, et al. The potential of self-assembled, $\mathrm{pH}-$ responsive nanoparticles of mPEGylated peptide dendron-doxorubicin conjugates for cancer therapy. Biomaterials, 2013, 34: 16131623

16 Duncan R. Development of HPMA copolymer-anticancer conjugates: Clinical experience and lessons learnt. Adv Drug Deliver Rev, 2009, 61: 1131-1148

17 Zhang R, Luo K, Yang J, et al. Synthesis and evaluation of a backbone biodegradable multiblock HPMA copolymer nanocarrier for the systemic delivery of paclitaxel. J Control Release, 2013, 166: 66-74

18 Zhang R, Yang J, Sima M, et al. Sequential combination therapy of ovarian cancer with degradable $\mathrm{N}$-(2-hydroxypropyl)methacrylamide copolymer paclitaxel and gemcitabine conjugates. Proc Natl Acad Sci USA, 2014, 111: 12181-12186

19 Luo Q, Xiao X, Dai X, et al. Cross-linked and biodegradable polymeric system as a safe magnetic resonance imaging contrast agent. ACS Appl Mater Interfaces, 2018, 10: 1575-1588

20 Yang J, Kopeček J. Design of smart HPMA copolymer-based nanomedicines. J Control Release, 2016, 240: 9-23

21 Noguchi Y, Wu J, Duncan R, et al. Early phase tumor accumulation of macromolecules: a great difference in clearance rate between tumor and normal tissues. Jpnese J Cancer Res, 1998, 89: 
307-314

22 Duan Z, Zhang Y, Zhu H, et al. Stimuli-sensitive biodegradable and amphiphilic block copolymer-gemcitabine conjugates self-assemble into a nanoscale vehicle for cancer therapy. ACS Appl Mater Interfaces, 2017, 9: 3474-3486

23 Li X, Sun L, Wei X, et al. Stimuli-responsive biodegradable and gadolinium-based poly[ $\mathrm{N}$-(2-hydroxypropyl) methacrylamide] copolymers: their potential as targeting and safe magnetic resonance imaging probes. J Mater Chem B, 2017, 5: 2763-2774

$24 \mathrm{Xu} \mathrm{W}$, Ledin PA, Shevchenko VV, et al. Architecture, assembly, and emerging applications of branched functional polyelectrolytes and poly(ionic liquid)s. ACS Appl Mater Interfaces, 2015, 7: 12570-12596

25 Venkataraman S, Hedrick JL, Ong ZY, et al. The effects of polymeric nanostructure shape on drug delivery. Adv Drug Deliver Rev, 2011, 63: 1228-1246

26 Kalyanaraman B, Joseph J, Kalivendi S, et al. Doxorubicin-induced apoptosis: Implications in cardiotoxicity. Mol Cellular Biochem, 2002, 234/235: 119-124

27 Chai $\mathrm{Z}, \mathrm{Hu} \mathrm{X}, \mathrm{Lu}$ W. Cell membrane-coated nanoparticles for tumor-targeted drug delivery. Sci China Mater, 2017, 60: 504-510

28 She W, Pan D, Luo K, et al. PEGylated dendrimer-doxorubicin cojugates as $\mathrm{pH}$-sensitive drug delivery systems: synthesis and in vitro characterization. J Biomed nanotechnol, 2015, 11: 964-978

29 Wei X, Luo Q, Sun L, et al. Enzyme- and pH-sensitive branched polymer-doxorubicin conjugate-based nanoscale drug delivery system for cancer therapy. ACS Appl Mater Interfaces, 2016, 8: $11765-11778$

30 Zhang C, Pan D, Luo K, et al. Dendrimer-doxorubicin conjugate as enzyme-sensitive and polymeric nanoscale drug delivery vehicle for ovarian cancer therapy. Polym Chem, 2014, 5: 5227-5235

31 Huang $\mathrm{X}, \mathrm{Du} \mathrm{F}, \mathrm{Ju} \mathrm{R}$, et al. Novel acid-labile, thermoresponsive poly(methacrylamide)s with pendentortho ester moieties. Macromol Rapid Commun, 2007, 28: 597-603

32 Song XR, Wang X, Yu SX, et al. $\mathrm{Co}_{9} \mathrm{Se}_{8}$ nanoplates as a new theranostic platform for photoacoustic/magnetic resonance dualmodal-imaging-guided chemo-photothermal combination therapy. Adv Mater, 2015, 27: 3285-3291

33 Shi K, Li J, Cao Z, et al. A pH-responsive cell-penetrating peptidemodified liposomes with active recognizing of integrin $\alpha_{\mathrm{v}} \beta_{3}$ for the treatment of melanoma. J Control Release, 2015, 217: 138-150

34 Tang M, Zhou M, Huang Y, et al. Dual-sensitive and biodegradable core-crosslinked HPMA copolymer-doxorubicin conjugate-based nanoparticles for cancer therapy. Polym Chem, 2017, 8: 2370-2380

35 Hickey JW, Santos JL, Williford JM, et al. Control of polymeric nanoparticle size to improve therapeutic delivery. J Control Release, 2011, 219: 536-547

$36 \mathrm{He} \mathrm{C,} \mathrm{Hu} \mathrm{Y,} \mathrm{Yin} \mathrm{L,} \mathrm{et} \mathrm{al.} \mathrm{Effects} \mathrm{of} \mathrm{particle} \mathrm{size} \mathrm{and} \mathrm{surface} \mathrm{charge}$ on cellular uptake and biodistribution of polymeric nanoparticles. Biomaterials, 2010, 31: 3657-3666

37 Felber AE, Dufresne MH, Leroux JC. pH-sensitive vesicles, polymeric micelles, and nanospheres prepared with polycarboxylates. Adv Drug Deliver Rev, 2012, 64: 979-992

38 Yuan YY, Mao CQ, Du XJ, et al. Surface charge switchable nanoparticles based on zwitterionic polymer for enhanced drug delivery to tumor. Adv Mater, 2012, 24: 5476-5480

39 Karimi M, Ghasemi A, Sahandi Zangabad P, et al. Smart micro/ nanoparticles in stimulus-responsive drug/gene delivery systems. Chem Soc Rev, 2016, 45: 1457-1501

40 Ben-Nun Y, Fichman G, Adler-Abramovich L, et al. Cathepsin nanofiber substrates as potential agents for targeted drug delivery. J Control Release, 2016, 257: 60-67

41 Sahay G, Alakhova DY, Kabanov AV. Endocytosis of nanomedicines. J Control Release, 2010, 145: 182-195

42 Chen K, Li X, Zhu H, et al. Endocytosis of nanoscale systems for cancer treatments. Curr Med Chem, 2017, 24: 1-1

43 Liu J, Bauer H, Callahan J, et al. Endocytic uptake of a large array of HPMA copolymers: Elucidation into the dependence on the physicochemical characteristics. J Control Release, 2010, 143: 7179

44 Li N, Cai H, Jiang L, et al. Enzyme-sensitive and amphiphilic PEGylated dendrimer-paclitaxel prodrug-based nanoparticles for enhanced stability and anticancer efficacy. ACS Appl Mater Interfaces, 2017, 9: 6865-6877

45 Jin W, Wang Q, Wu M, et al. Lanthanide-integrated supramolecular polymeric nanoassembly with multiple regulation characteristics for multidrug-resistant cancer therapy. Biomaterials, 2017, 129: 83-97

46 Zhang Z, Wang J, Nie X, et al. Near infrared laser-induced targeted cancer therapy using thermoresponsive polymer encapsulated gold nanorods. J Am Chem Soc, 2014, 136: 7317-7326

47 Malugin A, Kopecková P, Kopecek J. Liberation of doxorubicin from HPMA copolymer conjugate is essential for the induction of cell cycle arrest and nuclear fragmentation in ovarian carcinoma cells. J Control Release, 2007, 124: 6-10

48 Etrych T, Kovár L, Strohalm J, et al. Biodegradable star HPMA polymer-drug conjugates: Biodegradability, distribution and antitumor efficacy. J Control Release, 2011, 154: 241-248

49 Kostková H, Etrych T, Ríhová B, et al. HPMA copolymer conjugates of DOX and mitomycin $\mathrm{C}$ for combination therapy: physicochemical characterization, cytotoxic effects, combination index analysis, and anti-tumor efficacy. Macromol Biosci, 2013, 13: 1648-1660

50 Chytil $\mathrm{P}$, Koziolová E, Janoušková $\mathrm{O}$, et al. Synthesis and properties of star HPMA copolymer nanocarriers synthesised by RAFT polymerisation designed for selective anticancer drug delivery and imaging. Macromol Biosci, 2015, 15: 839-850

51 Su J, Sun H, Meng Q, et al. Long circulation red-blood-cell-mimetic nanoparticles with peptide-enhanced tumor penetration for simultaneously inhibiting growth and lung metastasis of breast cancer. Adv Funct Mater, 2016, 26: 1243-1252

Acknowledgements This work was supported by the National Natural Science Foundation of China (51673127 and 8162103), International Science and Technology Cooperation Program of China (2015DFE52780 and 81220108013) and International Science and Technology Cooperation Program of Chengdu (2016-GH03-00005-HZ).

Author contributions Chen $\mathrm{K}$ designed the study, performed the experiments, analyzed the data, and wrote the manuscript. Liao $S$ and Guo S performed experiments. Zhang $\mathrm{H}$ and Cai $\mathrm{H}$ analyzed the data, wrote the manuscript. Gong Q, Gu Z and Luo K designed the study, wrote the manuscript and they are responsible for funding support, resources and project administration.

Conflict of interest The authors declare that they have no conflict of interest.

Supplementary information Supporting data are available in the online version of the paper. 


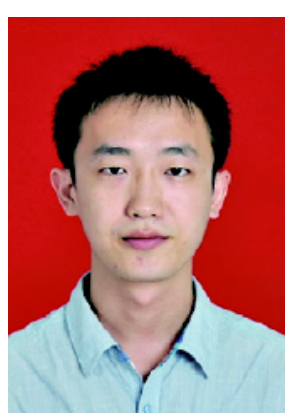

Kai Chen received his BSc degree from Army Medical University (Third Military Medical University), Chongqing, in 2015. Now he is a PhD candidate at the National Engineering Research Center for Biomaterials, Sichuan University. His current research focuses on the treatment of breast cancer with enzyme/pH sensitive polymer-drug conjugates-based nanoscale delivery system.

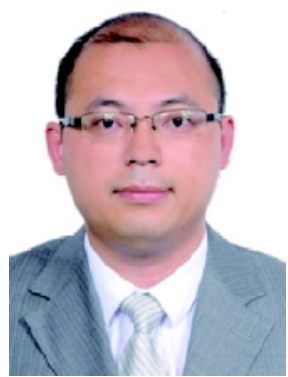

Kui Luo is a Professor in West China Hospital and National Engineering Research Center for Biomaterials, Sichuan University, China. He obtained his PhD degree from the National Engineering Research Center for Biomaterials, Sichuan University in 2009, and then became an assistant professor in this center. From 2009 to 2011, he carried out his postdoctoral work on polymeric nanomedicines at the Department of Pharmaceutics and Pharmaceutical Chemistry, University of Utah, USA. Dr. Luo was promoted to an associate professor in 2012 and Full Professor in 2013 in Sichuan University. From 2016, he was also a Full professor in Huaxi MR Research Center (HMRRC), Department of Radiology, West China Hospital, Sichuan University. His research focuses on stimuli-responsive and biodegradable polymeric gene/ drug delivery vehicles and imaging probes for cancer diagnosis and therapy, especially the study of synthetic macromolecules as potential cancer therapeutic and diagnostic agents, and the relationships between their actions and structural features.

\section{用于肿瘤治疗的酶/pH敏感的支化聚合物-阿䨢素偶联物}

陈凯 ${ }^{1,2}$, 廖爽斯 ${ }^{2,3}$, 郭仕伟 ${ }^{1,2}$, 张虎 $^{4}$, 蔡豪 $^{1,2}$, 龚启勇 ${ }^{2}$, 顾忠伟 ${ }^{1,2}$, 罗奎 ${ }^{1,2^{*}}$

摘要 本文设计了一种可生物降解的、肿瘤环境敏感的药物释放系统, 以达到安全、高效治疗癌症的目的. 我们利用单体 $N-(1,3-$ 二羟基2-丙基)甲基丙烯酰胺，通过可逆加成一断裂链转移聚合方法制备了含有对肿瘤细胞内组织蛋白酶B敏感的GFLG肽段的支化聚合物-药物 偶联物. 阿霉素通过 $\mathrm{pH}$ 敏感的腙键偶联到支化聚合物骨架上. 支化聚合物药物偶联物可自组装形成纳米粒, 平均粒径约为 $103 \mathrm{~nm}$. 连接到 聚合物载体的阿霉素可在酸性环境中释放. 较高分子量 $\left(M_{\mathrm{W}}, 220 \mathrm{kDa}\right)$ 的含有GFLG连接的支化聚合物一阿霉素偶联物可在组织蛋白酶B 的作用下降解为低分子量聚合物片段 $(<40 \mathrm{kDa})$. 支化偶联物通过内吞途径进入细胞, 然后释放抗癌药物, 进而对肿瘤细胞引起明显的细胞 毒性。偶联物的血液循环时间显著延长, 使得阿霉素在肿瘤部位大量蓄积. $4 \mathrm{~T} 1$ 荷瘤小鼠体内抗肿瘤实验表明, 支化偶联物的抗肿瘤效果 优于游离阿霉素. 此外, 体重测量和组织形态学检查的结果表明支化偶联物对正常组织的毒性很低. 因此, 这种对细胞内的酶和肿瘤组织 或细胞内的酸性 $\mathrm{pH}$ 具有响应性的支化聚合物给药系统在肿瘤靶向治疗中具有一定的前景. 